Review

\title{
Augmented, Virtual and Mixed Reality in Dentistry: A Narrative Review on the Existing Platforms and Future Challenges
}

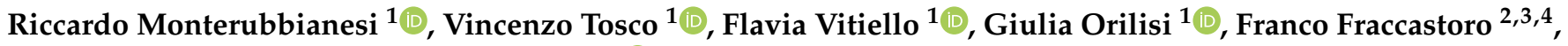 \\ Angelo Putignano ${ }^{1}$ and Giovanna Orsini ${ }^{1, * \mathbb{D}}$
}

check for updates

Citation: Monterubbianesi, R.; Tosco, V.; Vitiello, F.; Orilisi, G.; Fraccastoro,

F.; Putignano, A.; Orsini, G. Augmented, Virtual and Mixed Reality in Dentistry: A Narrative Review on the Existing Platforms and Future Challenges. Appl. Sci. 2022, 12, 877. https://doi.org/10.3390/ app12020877

Academic Editors: Enrico Vezzetti and Pietro Piazzolla

Received: 13 December 2021

Accepted: 11 January 2022

Published: 15 January 2022

Publisher's Note: MDPI stays neutral with regard to jurisdictional claims in published maps and institutional affiliations.

Copyright: (C) 2022 by the authors. Licensee MDPI, Basel, Switzerland. This article is an open access article distributed under the terms and conditions of the Creative Commons Attribution (CC BY) license (https:// creativecommons.org/licenses/by/ $4.0 /)$.
1 Department of Clinical Sciences and Stomatology, Polytechnic University of Marche, 60126 Ancona, Italy; r.monterubbianesi@univpm.it (R.M.); v.tosco@pm.univpm.it (V.T.); f.vitiello@pm.univpm.it (F.V.); g.orilisi@pm.univpm.it (G.O.); a.putignano@univpm.it (A.P.)

2 Steinberg Media Technologies GmbH, 20097 Hamburg, Germany; ffraccastorovhei@gmail.com

3 Department of History, Cultural Heritage, Education and Society, Tor Vergata University, 00133 Rome, Italy

4 IUDAV, Valletta Higher Education Institute, 83029 Solofra, Italy

* Correspondence: g.orsini@univpm.it

\begin{abstract}
The recent advancements in digital technologies have led to exponential progress in dentistry. This narrative review aims to summarize the applications of Augmented Reality, Virtual Reality and Mixed Reality in dentistry and describes future challenges in digitalization, such as Artificial Intelligence and Robotics. Augmented Reality, Virtual Reality and Mixed Reality represent effective tools in the educational technology, as they can enhance students' learning and clinical training. Augmented Reality and Virtual Reality and can also be useful aids during clinical practice. Augmented Reality can be used to add digital data to real life clinical data. Clinicians can apply Virtual Reality for a digital wax-up that provides a pre-visualization of the final post treatment result. In addition, both these technologies may also be employed to eradicate dental phobia in patients and further enhance patient's education. Similarly, they can be used to enhance communication between the dentist, patient, and technician. Artificial Intelligence and Robotics can also improve clinical practice. Artificial Intelligence is currently developed to improve dental diagnosis and provide more precise prognoses of dental diseases, whereas Robotics may be used to assist in daily practice.
\end{abstract}

Keywords: augmented reality; virtual reality; mixed reality; artificial intelligence; robotics; dentistry

\section{Introduction}

Currently, dentistry is benefiting from the development of modern digital transformation. Three-dimensional (3D) digital technology as well as computer-aided design and computer-aided manufacturing represent modern-day dentistry [1]. Nevertheless, innovations have been introduced in the dental field to improve dental education and clinical activity. Augmented Reality (AR) and Virtual Reality (VR) represent some of these innovations (Figure 1) and are part of the reality-virtuality continuum [2]. Commonly, traditional digital technologies in dentistry are structured into a three-step procedure which can be summarized as follows: (1) the digital image is acquired by a scanning device; (2) the operator can modify or change different dental aspect digitally, such as position or orientation of teeth; (3) the new information is transferred back to solid state or remain digital as a wax-up. With the introduction of AR and VR, these steps are simplified and implemented [3,4]. Although AR and VR possess many common aspects, the outcomes and the users' experience are completely different.

$\mathrm{AR}$ and VR systems require essential functionalities such as real and virtual data sources, tracking, registration techniques, visualization processing, perception locations, display types, and feedback mechanisms [5]. Instead of VR, AR generates an interaction 
between the real environment and virtual objects with the aim to combine virtual and real objects in a single real environment, to run interactively, and to register virtual and real objects reciprocally [6].

a

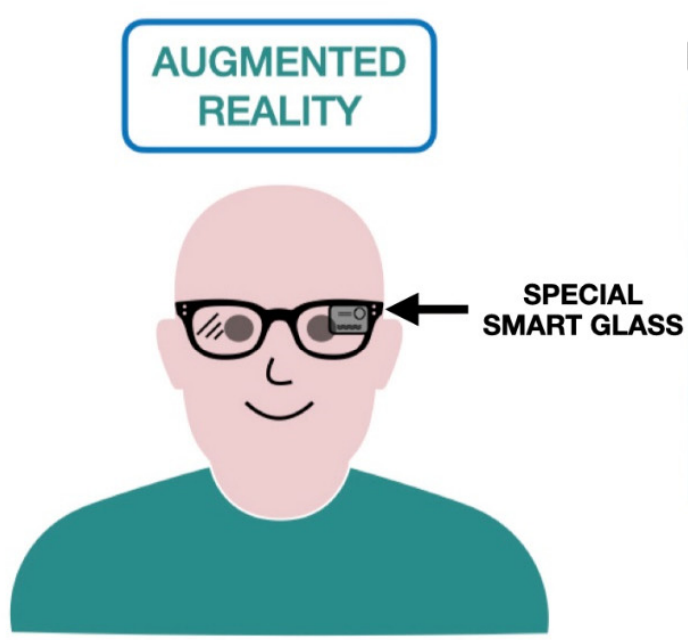

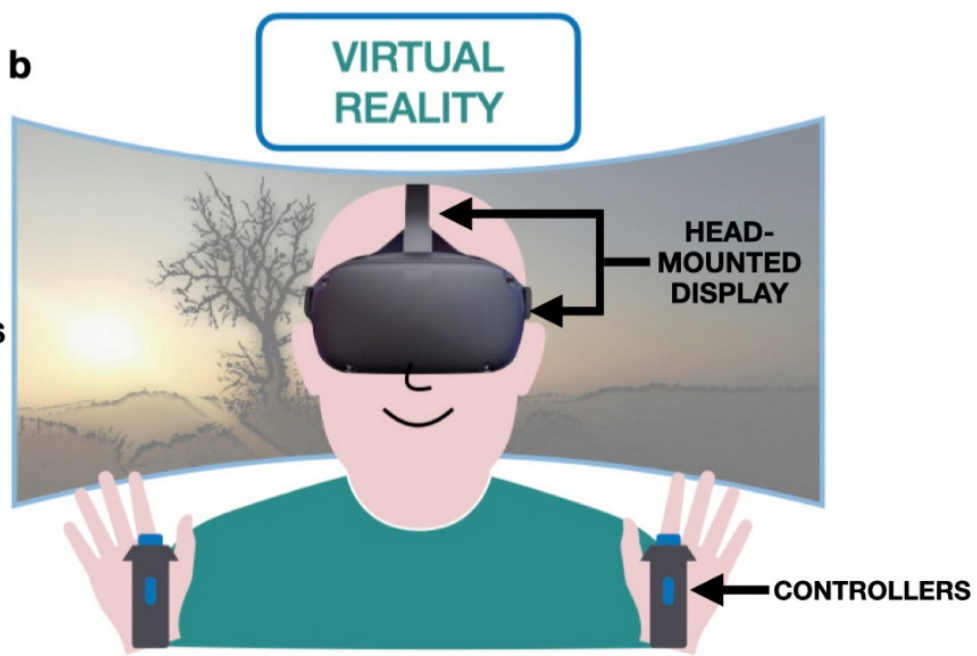

Figure 1. Illustrations of two examples of Augmented Reality (AR) and Virtual Reality (VR). (a) AR: the user sees the digital information superimposed with the reality by special smart glass (black arrow). (b) VR: the user is completely immersed in a virtual environment by head-mounted display (black arrows) and can interact with it using specific controllers (black arrow).

Monitor-based interfaces, monocular systems, head-mounted displays and other combined technologies are the instruments commonly used in AR systems. AR is mainly devoted to clinical practice in the medical field and improves the clinical procedure because it can allow clinical information to be visualized directly on the patient, overlapping the digital information and the real world [7]. In dentistry, the principal application of AR is related to overlapping digital information on the real world, basically "improving the reality" and live communication systems between patients and collaborators through the sharing of images, videos, and 3D models.

Conversely, VR uses customized and advanced software and hardware to create a digital 3D reality in which all user's senses are stimulated with computer-generated sensations and feedbacks. VR, therefore, allows participants to experience simulated digital realities similar to those of physical reality, thus creating scenarios that are impossible to experience in the real world [8]. VR differs from AR in three basic systems: scene generator, a display device, and tracking and sensing. In VR, the display and scene generator is employed to simulate the real world; thus, the resolution of the monitor becomes vital for real-time interaction with the virtual world, allowing the user to be immersed in a digitalbuilt reality [9]. Moreover, the user can use a specific device to interact with the virtual reality as a joystick and complex haptic systems (force feedback). VR applications are already in use in the dental field and mainly concern dental training: they allow students to simulate procedures in a virtual mouth, providing direct and immediate feedback.

In addition to AR and VR, Mixed Reality (MR) represents an innovative tool for use in dentistry. Despite MR being often confused with AR, it is a combination of AR and VR. In MR, users can interact with both virtual and real objects in real-time, while simultaneously, these objects can interact with each other. This "environment awareness" implies that not only do virtual objects act in the real environment, but real objects can also modify the virtual elements, regardless of where the experience is taking place [2]. For instance, in pure $\mathrm{MR}$, users would not be able to see a virtual instrument inside a drawer, unless they open it to look inside; in AR, the instrument would be overlaid, and it would be unnecessary to open the drawer. 
Innovations such as AI and Robotics are being introduced in the dental field. Whilst $\mathrm{AR}, \mathrm{VR}$ and MR enhance and create new realities, AI and Robotics perform and replicate human tasks. Artificial Intelligence (AI) revolves around its own intelligence, concerned in algorithm, to solve problems based on learning a specific set of data. Robotics focuses on the reproducibility of different clinical procedures. The use of these new systems could improve the way to perform the clinical training at dental schools and improve clinical practice, increasing the possibility of achieving better reproducible results in less time. At the best of authors' knowledge, there is no literature review that summarizes these novelties and their potential dental applications. For this reason, we decided to perform this narrative review aimed to recapitulate and provide an update about the actual uses and the possible applications of these new technologies in dentistry.

\section{Materials and Methods}

In agreement with the Scale for the Assessment of Narrative Review Articles [10,11], we conducted a keyword search-based literature for studies with abstracts or titles containing terms such as "Virtual Reality", "Augmented Reality", "Mixed Reality", "Artificial Intelligence", "Robotics". An electronic literature search was performed in PubMed, Scopus and Web of Science considering the articles published from January 2016 to August 2021. We limited this review to the dental field only and included English language-based international peer-reviewed articles (e.g., primary research, reviews, commentaries), online reports, electronic books, and press releases. We also applied a snowballing search methodology using the references cited in the articles identified in the literature search. The publications earlier than 2016 were cited when they were essential for advancing the discussion. The full-text articles of all potential studies were evaluated according to the predetermined inclusion and exclusion criteria listed in Table 1. Moreover, each identified item was assessed for relevance by a member of the study team. Figure 2 illustrates a flowchart of the search process. This narrative review presents an overview of the recent literature on the potential use of VR, AR, MR, AI and Robotics in the dental field.

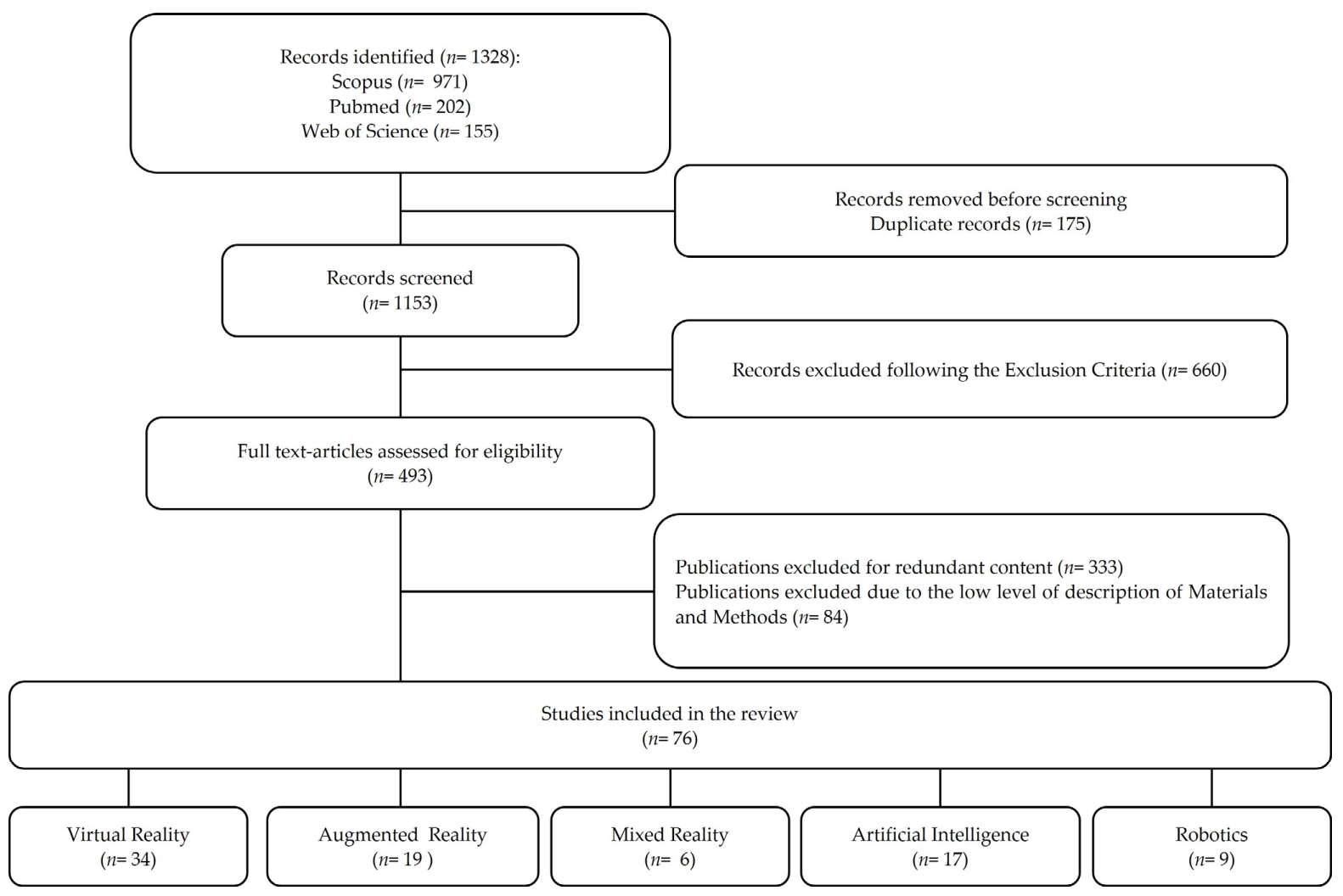

Figure 2. Flow chart of the literature selection process. 
Table 1. List of inclusion and exclusion criteria.

\begin{tabular}{l|l}
\hline \multicolumn{1}{c|}{ Inclusion Criteria } & \multicolumn{1}{c}{ Exclusion Criteria } \\
\hline $\begin{array}{l}\text { Original articles describing the application of } \\
\text { virtual, augmented and mixed reality, artificial } \\
\text { intelligence, and robotics in dentistry (at least } \\
\text { one of them) }\end{array}$ & $\begin{array}{l}\text { Opinion or narrative discussions that did not } \\
\text { report on the use of virtual and or augmented } \\
\text { reality, artificial intelligence, and robotics in } \\
\text { dentistry. }\end{array}$ \\
$\begin{array}{l}\text { Publable in the English language } \\
\text { Detailed programming for virtual reality, } \\
\text { professional journals }\end{array}$ & $\begin{array}{l}\text { abstracts, conference proceedings, letters to the } \\
\text { editor and, case reports were excluded. }\end{array}$ \\
\hline
\end{tabular}

\section{Results}

During the retrieval of the scientific literature on the potential uses of $\mathrm{VR}, \mathrm{AR}, \mathrm{MR}, \mathrm{AI}$ and Robotics in the dental field, we found research from multiple disciplines, such as dental education, restorative dentistry, endodontics, dental surgery, preventive dentistry and dental phobia. This narrative review investigated not only the application of these devices, but also the efficacy on their use, comparing them with similar devices or traditional tools used during standard protocols.

The findings presented below represent a summary of recent examined studies.

\subsection{Applications in Teaching Dental Morphology}

The study of anatomy is commonly performed by using static two-dimensional (2D) images such as lecture slides, textbooks and flashcards [12]. Since anatomical structures are in three-dimensions (3D), the comprehension of spatial relationships using such static 2D images may be difficult.

Through 3D virtual models, different anatomical structures may be visualized, making the learning experience more immersive than the traditional 2D and 3D methods [13]. The exploration of a virtual environment may help to develop spatial knowledge, reducing the gap between students who struggle to visualize spatial structures and those confident in their spatial ability [14]. In addition, Küçük et al. highlighted that dental students appear more interested in learning anatomical structures through a 3D model than through traditional 2D methods [15].

AR and VR may also be used to learn dental morphology and tooth features such as exterior shape, position, size and internal structure. Basing on software programs with interactive data set, the tooth can be selected, moved and visualized from different directions and angulations. Moreover, specific tooth structures can be made transparent such that the users can see beyond them or even navigate through the root canal. Reymus et al. tested the use of VR in teaching root canal anatomy and found that VR appears to be a valuable instrument suitable for training a student [16]. Thus, both VR and AR may be considered valuable platforms for teaching anatomy and promoting benefits such as increased learner immersion, even if there are no statistically significant differences regarding the amount of knowledge acquired by VR/AR and the traditional method [16].

\subsection{Applications in Pre-Clinical Education}

A significant proportion of dental education is dedicated to teaching clinical psychomotor skills, and often, the dentist trains directly on the patient [17]. Currently, dental schools use realistic patient simulators with dental models incorporated to simulate a dental treatment [18]. These simulators allow the instructors to demonstrate techniques aimed at improving the hand-eye coordination and manual dexterity of students. Moreover, during the activities on the simulators, dental students require constant tutor feedback on their work for understanding better the procedures before moving on to the subsequent procedures.

During the COVID-19 pandemic, limitations in pre-clinical education have been highlighted, as many dental students could not be trained at their university and lacked the direct support of the tutor. In this COVID-19 era, the most important issue for pre-clinical and clinical education is achieving the balance between the training of dental students and limiting the spread of infected cases $[19,20]$. It is for this reason, because of the development 
of innovative instruments to train and teach the basic clinical procedures to the dental students, that replicating dental reality as much as possible became of paramount importance.

Considering these aspects, AR, VR and MR represent innovative educational tools which allow self-education of the student. While the description of the tactile sensation of clinical procedures by the tutor may be difficult to explain using the traditional simulator, the presence of direct feedback and pressure sensors may be useful to overcome this problem by using VR or MR [21]. In a previous study by Eve et al., the performance on a simulated caries removal of undergraduate dental students was compared to prosthodontics residents using a novel haptic VR simulator [22]. Their results showed that efficiency, defined as percentage of carious lesion removed over drilling time, improved significantly over the experiment for both novice and experienced operators [22]. In addition, De Boer et al. examined the use of VR in dental education and highlighted a significant positive effect on the student performance and the appreciation of the 3D environment compared to 2D [23].

Similar to traditional simulators, VR or MR simulators provide digital teeth models, digital handpieces equipped with an air and water in-and-out system and different types of digital burs. In addition, these simulators may provide instant feedback for the students making full use of the lab training time and improving students' manual dexterity skills before confidently moving onto clinical setting with patients. Table 2 summarizes and compares different dental simulators currently used [21].

Table 2. Comparison of different dental simulators.

\begin{tabular}{|c|c|c|c|c|c|c|}
\hline & PerioSim $^{\circledR}$ & Dentsim $^{\mathrm{TM}}$ & IDEA & Simodont $^{\circledR}$ & Voxel Man & CDS \\
\hline Teeth Used & Animated & Plastic teeth & Animated & Animated & Animated & Animated \\
\hline $\begin{array}{l}\text { Right And Left } \\
\text { Operation }\end{array}$ & Available & Available & Available & Available & Available & Available \\
\hline $\begin{array}{c}\text { Reported Real } \\
\text { Life } \\
\text { Experience }\end{array}$ & $\begin{array}{l}\text { Tactile } \\
\text { sensation is } \\
\text { realistic for } \\
\text { teeth but not for } \\
\text { gingiva }\end{array}$ & $\begin{array}{c}\text { Realistic } \\
\text { experience } \\
\text { using plastic } \\
\text { teeth on a real } \\
\text { manikin }\end{array}$ & $\begin{array}{l}\text { Tactile } \\
\text { sensation still } \\
\text { needs to be } \\
\text { tuned to } \\
\text { simulate a } \\
\text { genuine } \\
\text { sensation }\end{array}$ & $\begin{array}{l}\text { 3D images are } \\
\text { realistic. However, } \\
\text { the texture of } \\
\text { healthy } \\
\text { decayed and } \\
\text { restored } \\
\text { tooth structure still } \\
\text { needs } \\
\text { improvement }\end{array}$ & / & / \\
\hline \multirow[t]{2}{*}{$\begin{array}{l}\text { Ergonomic } \\
\text { Postures }\end{array}$} & No & Yes & No & Yes & No & Yes \\
\hline & Not available & Yes & Yes & Yes & Not available & Yes \\
\hline $\begin{array}{l}\text { Direct Transfer of } \\
\text { Data to Program } \\
\text { Instructor/Tutor }\end{array}$ & & $\begin{array}{l}\text { Run time control. } \\
\text { Application } \\
\text { enables the } \\
\text { instructor to } \\
\text { control run time } \\
\text { grades. }\end{array}$ & $\begin{array}{l}\text { The software } \\
\text { contains a } \\
\text { replay mode. } \\
\text { Upon } \\
\text { completion of a } \\
\text { specified task, it } \\
\text { can be watched } \\
\text { in full by the } \\
\text { student or the } \\
\text { instructor. }\end{array}$ & $\begin{array}{l}\text { Allows the } \\
\text { instructor to } \\
\text { watch six } \\
\text { simulators } \\
\text { live at once and } \\
\text { record all } \\
\text { preparations for } \\
\text { evaluation in order } \\
\text { to give } \\
\text { feedback later. }\end{array}$ & & $\begin{array}{l}\text { Operating } \\
\text { procedures are } \\
\text { recorded and } \\
\text { can be reviewed } \\
\text { to facilitate in } \\
\text { training, grading } \\
\text { and verifying. }\end{array}$ \\
\hline Instant Feed Back & No & Yes & Yes & Yes & Yes & Yes \\
\hline Exam Simulation & Yes & Yes & No & Yes & Yes & Yes \\
\hline
\end{tabular}

\subsection{Applications in Clinical Practice}

The medical applications of AR are currently concentrated on different surgery types, including neurosurgery, laparoscopic surgery, and plastic surgery. In dentistry, AR is primary used in oral and maxillofacial surgery, dental implant placement and orthognathic surgery [24]. The development of AR devices allows the user to combine the medical information, medical data, and images to the reality. In contrast to conventional image-guided 
surgery, where a surgeon often looks away from the operative field to view the informative data, AR guidance systems provide real-time intraoperative information directly on the surgical fields and this may decrease the surgical risk [25].

In dental implant placement, AR has been shown to substantially improve a wide range of procedures. A dental implant positioning system with a graphically superimposed suggested position on the patient was introduced as early as 1995. The AR surgical navigation systems for implant placement were introduced using retinal imaging display such that the surgeon maintains the view of the operative field without looking away [26]. During implant placement, AR can act as automatic information filters that selectively display only the most relevant information to surgeons, thereby helping them concentrate fully on the implant placement thereby reducing time and additional costs [27].

Orthognathic surgery is one of the most widely used fields of AR applications in dentistry. The most important advantage of AR-based navigation systems for orthognathic surgery is the possibility to provide overlaid images of real surgical views and virtual surgical plans for guidance. The systems overlay these models onto real-time streaming video images to provide surgeons with preoperative planning and anatomical information. Different AR-based systems were introduced for the simulation of the reduction of mandibular angle and the simulation of the mandibular reconstructive surgery [28-30]. Innovative systems were also developed to simulate mandibulectomy and fibular transplant to the mandibular defect site using 3D patient mesh models. In addition, it allowed surgeons to test and find configurations of vessels and skin paddles [31]. Kim et al. used an AR-system to display overlaid images to allow surgeons to follow virtual surgical plans when repositioning patient bones after maxillofacial osteotomies [32].

Even VR was applied in orthognathic surgery in order to train different procedures of orthognathic maxillofacial surgery. To better simulate the surgical procedures the VR system can include and replicate different functions such as bone sawing, drilling, and place fixation with haptic force feedback [28,33]. Moreover, in another VR-based simulation platform, the surgeon can interact with the virtual world naturally using his or her hands by means of a tracked hand-held controller [34].

\subsection{Applications in Dental Phobia}

It is estimated that $50-60 \%$ of individuals suffer from a specific fear of dental procedures and dental-related stimuli, or from a mild to severe grade of dental anxiety [35,36]. Fear-related behaviours are considered the most difficult aspect of dental patient management and may interfere with good dental care since the patient with dental phobia (named "odonto-phobia") goes to the dentist when the clinical situation is severe. The therapeutic techniques, considered most effective in the treatment of phobias and fears, are the In Vivo Exposure Therapy (IVET) and the Virtual Reality Exposure Therapy (VRET). IVET is a technique based on direct patient confrontation with an object or series of anxious situations to reduce the consequent anxious reaction. This exposure therapy is considered the gold standard therapy in the treatment of specific fears related to the dental care situation [37]. Recently, VRET has become a viable alternative to IVET in the treatment of specific phobias [38]. Using computer-generated VR environments, the patient is gradually exposed to situations which are potentially sources of anxiety [39]. Compared to IVET, VRET is safer because the patients face the virtual representation of their threat more gradually in a controlled manner [40]. VRET is known to elicit a feeling of being "present" in the virtual environment, and this represents the main factor for the effectiveness of VRET [41]. Clinically, techniques such as cognitive-behavioural treatments, nitrous oxide, and intravenous sedatives administered during dental treatments have been found to minimize patient pain and discomfort during dental care [42,43]. In addition to these invasive methods, distracting patients with a movie has been shown to help reduce pain in some medical procedures and during laboratory studies of pain [44]. Following the same concept, VR can serve as an effective non-pharmacologic analgesic for dental pain [45]. Several studies reported that VR reduced their awareness of dental pain and that they were so absorbed in 
the VR that they did not think often about their pain [46-48]. The patient's inability to see the dental practitioner and instruments may be one advantage of VR. The effectiveness of VR distraction treatment may depend on how patients feel in the virtual environment [49]. For this reason, video stimulation and audio simulation may be detrimental in making the users' experience more immersive and by trying to decrease the dental pain [8]. For VR application, it is advisable to produce sound in three dimensions, specifically in the binaural format.

The audio in three dimensions allows the users to hear the sound of objects according to their position in the virtual space. The use of the binaural format, which reproduces the immersive audio with simple headphones, without the aid of a complex hardware set up, will create a greater reality of the VR environment [8]. Consequently, the effectiveness of VR in distracting the patient from medical treatment will be greater. Hendrix et al. confirmed that 3D sound increases people's sense of immersion in virtual reality [50]. The study showed that people felt more immersed in virtual realities with spatial sound than in virtual realities with non-spatial sound [50,51]. Moreover, the soundtrack in an immersive audio, more than the stereo format, increases the possibility of modifying the patient's state of mind. Therefore, an adequate sonorization of the VR environment will favour a state of calm and relaxation.

\subsection{Applications in Patient Education}

Educational and motivational methods play an important role in informing individuals about their oral health status, including oral pathologies that affect oral tissues, thus helping to enhance their compliance with oral care at home. In particular, oral health education is effective in improving patient's attitude and practice of oral hygiene, providing useful devices and techniques for dental plaque control, which may promote gingival health and decrease caries occurrence [52,53].

AR and VR can be considered important tools to educate old and young patients. The expected outcome in using VR and AR for oral home care is to provide a digital instrument to improve oral hygiene practice in children and adults, motivating the prevention of oral diseases and making educational practices attractive. Moreover, by using games or educational interfaces, VR and AR may become important accessories in the process of teaching and learning. Although few articles reported the application of VR in patient education, it seems to be an engaging learning tool, and patients who participated in the studies perceived it to be beneficial in understanding their health status [54,55]. Mainly in children, the advantage in using a game consists on: whenever the player executes the brushing technique incorrectly, the system provides a visual response which allows the patient to correct the brushing technique. However, further efforts to investigate the role of VR in education and oral health care should be explored in the future.

\subsection{Dentist-Patient Communication Tools}

Clinicians use several tools to collect different data in order to formulate the correct functional and aesthetic treatment plan such as [56]: physical examination, radiographs, study models, intraoral and extraoral photographs. Once the diagnosis has been made, the patient must be informed of the chosen therapeutic modalities, based on his clinical situation and on evaluating psychological and socio-economic aspects. Nevertheless, many patients may not have the necessary knowledge to understand the concepts illustrated for the treatment plan and the condition of their oral cavity; thus, it may be difficult for the dentist to persuade the patient to accept the proposed therapeutic option.

In this light, digital dentistry has led to the development of many innovative technologies that can aid the dentist in communicating with the patient; for example, the spread of digital technology has simplified the step of creating a set of facial and intraoral photographs, both in the production phase of the images and in their archiving. In addition to communication purposes, this allows the dentist to analyse the patient even after the actual visit, exchanging information with the dental laboratory and with colleagues who 
may participate in the execution of the therapies [57]. Currently, different devices can be used to improve such patient-operator communication, as diagnostic and virtual wax-up allow for the visualization of the possible prosthetic treatment.

Predicting outcomes of the therapy offers many advantages in terms of communication, design and economics. Providing an image in which the result is represented may improve the relationship of trust with the patient and simplify the transmission of the necessary data to the dental technician.

\subsection{Artificial Intelligence and Robotics}

In addition to AR and VR, new technologies, such as AI and Robotics, have been applied in dentistry to improve the clinical practice [58]. AI is the ability of a machine to perform human tasks and revolves around its own intelligence to solve problems based on the learning of a specific set of data. AI refers to any machine or technology that can mimic human cognitive skills such as problem solving. The foundation of $\mathrm{AI}$ is to increase the ability of machines or its intelligence components to perform tasks with speed, low resources, accuracy, and precision. Machine learning is part of AI, which depends on algorithms to predict outcomes based on a dataset [59]. Algorithms are artificial neural networks, highly interconnected networks of computer processors inspired by biological nervous systems that function similarly to the human brain [60].

The most active areas of medical AI are diagnostics and prediction of prognoses. AI in the medical sector contributes significantly to helping decision making related to medical practice, while presenting a considerable level of potential for sound diagnosis and prediction $[61,62]$. It was proven that machine learning, based on data derived from the decisions of dental professionals, achieved significant performance [63]. For example, different studies intended to generate caries prediction models to facilitate the likelihood calculation of an individual developing dental caries based on clinical findings or demographic and lifestyle factors $[63,64]$. Another important feature is data mining, whose strength lies in the ability of finding causal relationships and comparisons that are innate in existing data [65]. The observations were obtained by data mining analysis, while the only role of dental professional was to collect and tabulate the data.

All the above studies proved the application of AI in the current dental field to diagnose and make prognoses through extrication of useful information from large amounts of medical records [65]. Again, data mining analysis performed on a bulk of restorative data of patients revealed that differences in the material of dental restorations serve as important factors determining the lifespan of a restoration [66]. Currently, studies applying machine learning based on artificial neural networks to dental treatment through analysis of dental magnetic resonance imaging, computed tomography, and cephalometric radiography are actively underway. AI-based systems are often used for designing software programs that try to simplify data management and diagnosis in dentistry. Mostly, they are clinical decision support systems that assist and guide experts to make better decisions [67] and aesthetic mock-up [68].

AI-based systems have been used for better diagnosis, treatment planning and for prognosis prediction. AI in dentistry started procuring its role with emergence of data computation and availability of large amounts of patient data. For instance, the information acquired by radiological exam can be analysed by an algorithm which may improve and help the diagnosis and treatment phases of oral pathology and disease in an automatic way [65]. Additionally, AI technology has demonstrated excellent results in the detection of dental caries [69,70], diagnosing oral squamous cell carcinoma [71], and evaluation of the correct working length in endodontics [72-74].

In adjunct to AI, robotics can represent the next frontier of dentistry. Robotics has been added to medicine since 1992, but only in 2001, a human-controlled robot, remotely located, was able to remove a dental caries, perform an endodontic treatment and execute a crown and bridge preparation [75]. 
In 2017, Yuan et al. demonstrated that robots' tooth preparation skills, such as laminate veneer and crowns preparations, are as accurate as those of human dentists [76]. Recently, a mobile wire-bending machine was introduced, which is capable of creating a fixed orthodontic retainer wire by means of intraoral scan data in only four minutes [77]. Another remarkable opportunity enabled by robotics is computer-assisted surgery. Using this approach, a navigation system may track the position of a surgical device in real time. The guidance to the dentist is realized by the device position projecting onto the digital image of the anatomic area of interest, providing help in real-time to follow the anticipated pathways and allowing the doctor to recognize possible interference with the neighbouring tissues. Currently, the most commonly used optical tracking systems are based on capturing the position of a series of light-emitting diodes mounted on a surgical device [77]. In the future, virtual robotic surgery will allow surgeons to operate patients in a different location.

\section{Discussion}

This narrative review depicts the potential application of VR, AR and MR, AI and Robotics in dentistry. The decision to provide a narrative review could be considered as a limitation of this study; however, it allows the provision of an accurate overview of the recent scientific literature on the potential use of $\mathrm{VR}, \mathrm{AR}, \mathrm{MR}, \mathrm{AI}$ and Robotics in the dental field. The broad perspective might become lost using a systematic review, since it focuses on a specific query, as in PRISMA guidelines [78]. As reported in the scientific literature, a narrative review summarizes the literature in a way which is not explicitly systematic, but it is suited to addressing a topic in wider ways [10].

In the field of dental education, VR and AR can improve the teaching of dental morphology from both an economic and practical standpoint. The use of cadavers or synthetic recreations (silicone or plastic models) represents the current gold standard for studying head and neck anatomy in dental schools and postgraduate courses. AR and VR are reusable, unlike cadavers and synthetic recreations, making them more economically viable. They can also enhance visualization of anatomical structures, thereby improving understanding of dental structures. Furthermore, using these new technological approaches may promote students' motivation and interest in learning.

The use of virtual simulators in professional education programs can allow students to refine their clinical skills without the risk of harming a patient during the learning process and, in this era of COVID-19, to certainly avoid potential infection [17]. Using VR, AR or MR simulators, a more realistic training could also support and reinforce ergonomics, thus improving the students' preclinical experience [79]. The type of simulation chosen by the dental student can range from simple cavity preparation to more complex overlay or crown preparation. The virtual simulator may give direct feedback to the student and therefore improve clinical skills in a faster and safer manner. Although VR, AR and MR may improve the dental education, more information about their learning theories are required [80]. Makransky et al. investigated the process of learning of immersive reality systems and highlighted the need to develop learning theories by using a research-based theoretical model so that personnel such as students, teachers, and instructional designers would possess the correct knowledge for adopting such devices [80]. Moreover, a recent review revealed that few design-oriented studies constructed their VR applications based on a specific learning theory, which serves as technical development guidance [81].

Apart from dental education, AR and VR may help to reshape clinical dentistry. Computer-generated information may be superimposed on the surgical field using AR and VR [82]. These technologies may reduce the time needed for consulting digital information, but more importantly, they allow the clinician to focus on the patient.

The application of AR and VR in clinical practice may not only be useful for dental students and clinicians as previously discussed, but also for patients. AR and VR can present suitable specific non-invasive strategies to reduce dental anxiety and treat dental phobias, one of our society's phobic conditions [38]. AR and VR could represent useful aids to manage or even overcome dental phobias, such as by using videogames or even by 
the total immersion of the patient into a virtual environment. These technologies can be used to implement oral health education strategies. For example, teaching toothbrushing techniques could become more feasible, effective, and accessible to children by linking learning with fun [83]. Consequently, AR and VR based-games may also be customized to correct brushing techniques after identifying mistakes [84].

These innovative technologies can improve communication between dental practitioners, dental technicians, patients, and the multidisciplinary team. VR allows the clinician to demonstrate to patients the expected clinical outcome via a total virtual simulation. However, AR may allow for an immediate interaction between the dentist and patient. An AR device can create a 3D model that can be placed directly in the patient's mouth, therefore providing $3 \mathrm{D}$ visualization for aesthetic planning [85]. An AR system can share the operator's reality with the dental technician or another specialist when formulating a treatment plan.

$\mathrm{AI}$ and Robotics represent the new frontiers of digital dentistry. The artificial nature of AI allows for the elimination of potential human error, bias and feelings such as fatigue, tiredness, and boredom, which can manifest after repetitive work [86]. Human intelligence is denoted by perception and interpretation. AI cannot replace human intelligence but can instead support human interpretation and action. AI machines develop problem-solving abilities through independent learning and by utilizing human senses and mechanisms of the human mind [61]. The realization of machines learning through a bio-inspired artificial neural network is a widely used method in AI [87]. These innovative features of AI can be applied to medical decision making, offering the possibility of helping clinicians obtain expert-level information [88]. As the use of AI increases in the medical field, the role of AI in dentistry may also expand and become a reliable and friendly tool used in daily practice.

While AI helps in developing diagnosis and prognosis, robotics can assist clinicians through computer-assisted interventions. Robot dental assistants and other applications are promising; however, critical challenges limit progress, such as high costs and complex operability of the systems. Further research is needed, as the latest changes in modern robot technology have not yet been fully introduced to dental research nor have they reached technological readiness and cost efficiency to enter the dental market [58].

Data provided by multiple digital technologies, such as photographs or 3D-tracking devices, radiographic information, or intraoral images, can be integrated using these novel technologies. This integrated digital information allows for the creation of a digital patient ("virtual patient"). A clinician can then use the "virtual patient" to directly develop a digital treatment plan on screen. Possible uses include the simulation of the procedures such as surgical navigation for implant placement, design of restorations, or navigated endodontics. Moreover, using different virtual patients can allow for a patient-centred approach driven by patient-centred outcomes.

Although this work made an overview of the potential use of VR, AR, MR, AI and Robotics in dentistry, information about their precise application in the different disciplines is still lacking. Moreover, limited data are available regarding the effect of such devices on the cognitive load of the users. While a recent systematic review reported a lower or equal cognitive load of these new devices with higher performance, when compared to more traditional conditions such as display- or paper-based instructions [89], data regarding the cognitive load during their clinical or educational applications are still missing. Ethical aspects, learning theories and cognitive load should be further investigated to better exploit their potential.

\section{Conclusions}

Modern digital technologies can potentially reshape dentistry both on an educational and clinical level. Students may improve their knowledge and practical skills. Dental clinicians may use these technologies as useful aids in their practice. Despite the promising development of AI and Robotics in dentistry, their actual application remains primarily experimental. Future research on digitalization in healthcare, especially dentistry, should 
certainly focus on improving AR, VR, AI and Robotics since they can all represent modern and strategic approaches that may ensure qualitative efficient dental care.

Author Contributions: Conceptualization, G.O. (Giovanna Orsini), R.M. and F.F.; methodology, R.M., F.V., V.T., F.F. and G.O. (Giovanna Orsini); validation, G.O. (Giulia Orilisi), F.F., A.P. and G.O. (Giovanna Orsini); formal analysis, R.M., V.T., F.V. and G.O. (Giulia Orilisi); investigation, R.M. and V.T.; resources, A.P. and G.O. (Giovanna Orsini); data curation, V.T., F.V. and G.O. (Giulia Orilisi); writing - original draft preparation, R.M. and F.V.; writing—review and editing, R.M., V.T., F.V., G.O. (Giulia Orilisi), F.F. and G.O. (Giovanna Orsini); visualization, F.V., F.F. and A.P.; supervision, A.P. and G.O. (Giovanna Orsini); project administration, A.P. and G.O. (Giovanna Orsini); funding acquisition, A.P. and G.O. (Giovanna Orsini). All authors have read and agreed to the published version of the manuscript.

Funding: SISOPD (Società Italiana Stomatologia, Odontoiatria e Protesi Dentaria-Italian Society of Dentistry, Stomatology and Prosthodontics) partially supported this study. The sponsor had no role in design, analysis, and interpretation of the study.

Data Availability Statement: The data presented in this study are available on request from the corresponding author.

Acknowledgments: The authors extend their gratitude to Valentina Ragni for their precious support in database searching. Andrell Hosein is kindly acknowledged for her support in English editing.

Conflicts of Interest: The authors declare no conflict of interest.

\section{References}

1. Orsini, G.; Tosco, V.; Monterubbianesi, R.; Orilisi, G.; Putignano, A. A New Era in Restorative Dentistry. In The First Outstanding 50 Years of "Università Politecnica delle Marche": Research Achievements in Life Sciences; Longhi, S., Monteriù, A., Freddi, A., Aquilanti, L., Ceravolo, M.G., Carnevali, O., Giordano, M., Moroncini, G., Eds.; Springer International Publishing: Cham, Switzerland, 2020; pp. 319-334. ISBN 978-3-030-33832-9.

2. Flavián, C.; Ibáñez-Sánchez, S.; Orús, C. The Impact of Virtual, Augmented and Mixed Reality Technologies on the Customer Experience. J. Bus. Res. 2019, 100, 547-560. [CrossRef]

3. Favaretto, M.; Shaw, D.; De Clercq, E.; Joda, T.; Elger, B.S. Big Data and Digitalization in Dentistry: A Systematic Review of the Ethical Issues. Int. J. Environ. Res. Public Health 2020, 17, 2495. [CrossRef] [PubMed]

4. Zitzmann, N.U.; Matthisson, L.; Ohla, H.; Joda, T. Digital Undergraduate Education in Dentistry: A Systematic Review. Int. J. Environ. Res. Public Health 2020, 17, 3269. [CrossRef] [PubMed]

5. Huang, T.-K.; Yang, C.-H.; Hsieh, Y.-H.; Wang, J.-C.; Hung, C.-C. Augmented Reality (AR) and Virtual Reality (VR) Applied in Dentistry. Kaohsiung J. Med. Sci. 2018, 34, 243-248. [CrossRef]

6. Joda, T.; Bornstein, M.M.; Jung, R.E.; Ferrari, M.; Waltimo, T.; Zitzmann, N.U. Recent Trends and Future Direction of Dental Research in the Digital Era. Int. J. Environ. Res. Public. Health 2020, 17, 1987. [CrossRef]

7. Farronato, M.; Maspero, C.; Lanteri, V.; Fama, A.; Ferrati, F.; Pettenuzzo, A.; Farronato, D. Current State of the Art in the Use of Augmented Reality in Dentistry: A Systematic Review of the Literature. BMC Oral Health 2019, 19, 135. [CrossRef]

8. Fraccastoro, F. Dal Mono al Suono Immersivo in Il Suono Immersivo, 1st ed.; Paguro Edizioni: Salerno, Italy, 2021; Volume 5, pp. $23-44$.

9. Joda, T.; Gallucci, G.O.; Wismeijer, D.; Zitzmann, N.U. Augmented and Virtual Reality in Dental Medicine: A Systematic Review. Comput. Biol. Med. 2019, 108, 93-100. [CrossRef]

10. Baethge, C.; Goldbeck-Wood, S.; Mertens, S. SANRA-A Scale for the Quality Assessment of Narrative Review Articles. Res. Integr. Peer Rev. 2019, 4, 5. [CrossRef]

11. Green, B.N.; Johnson, C.D.; Adams, A. Writing Narrative Literature Reviews for Peer-Reviewed Journals: Secrets of the Trade. J. Chiropr. Med. 2006, 5, 101-117. [CrossRef]

12. Chiodera, G.; Orsini, G.; Tosco, V.; Monterubbianesi, R.; Manauta, J.; Devoto, W.; Putignano, A. Essential Lines: A Simplified Filling and Modeling Technique for Direct Posterior Composite Restorations. Int. J. Esthet. Dent. 2021, 16, $168-184$.

13. Iwanaga, J.; Kamura, Y.; Nishimura, Y.; Terada, S.; Kishimoto, N.; Tanaka, T.; Tubbs, R.S. A New Option for Education during Surgical Procedures and Related Clinical Anatomy in a Virtual Reality Workspace. Clin. Anat. 2021, 34, 496-503. [CrossRef] [PubMed]

14. Uruthiralingam, U.; Rea, P.M. Augmented and Virtual Reality in Anatomical Education-A Systematic Review. Adv. Exp. Med. Biol. 2020, 1235, 89-101. [CrossRef] [PubMed]

15. Küçük, S.; Kapakin, S.; Göktaş, Y. Learning Anatomy via Mobile Augmented Reality: Effects on Achievement and Cognitive Load. Anat. Sci. Educ. 2016, 9, 411-421. [CrossRef] [PubMed]

16. Reymus, M.; Liebermann, A.; Diegritz, C. Virtual Reality: An Effective Tool for Teaching Root Canal Anatomy to Undergraduate Dental Students-A Preliminary Study. Int. Endod. J. 2020, 53, 1581-1587. [CrossRef] 
17. Moussa, R.; Alghazaly, A.; Althagafi, N.; Eshky, R.; Borzangy, S. Effectiveness of Virtual Reality and Interactive Simulators on Dental Education Outcomes: Systematic Review. Eur. J. Dent. 2021. [CrossRef]

18. Suvinen, T.I.; Messer, L.B.; Franco, E. Clinical Simulation in Teaching Preclinical Dentistry. Eur. J. Dent. Educ. 1998, 2, 25-32. [CrossRef]

19. Ball, C.; Huang, K.-T.; Francis, J. Virtual Reality Adoption during the COVID-19 Pandemic: A Uses and Gratifications Perspective. Telemat. Inform. 2021, 65, 101728. [CrossRef]

20. Tabatabai, S. COVID-19 Impact and Virtual Medical Education. J. Adv. Med. Educ. Prof. 2020, 8, 140-143. [CrossRef]

21. Roy, E.; Bakr, M.M.; George, R. The Need for Virtual Reality Simulators in Dental Education: A Review. Saudi Dent. J. 2017, 29 , 41-47. [CrossRef]

22. Eve, E.J.; Koo, S.; Alshihri, A.A.; Cormier, J.; Kozhenikov, M.; Donoff, R.B.; Karimbux, N.Y. Performance of Dental Students versus Prosthodontics Residents on a 3D Immersive Haptic Simulator. J. Dent. Educ. 2014, 78, 630-637. [CrossRef]

23. de Boer, I.R.; Wesselink, P.R.; Vervoorn, J.M. Student Performance and Appreciation Using 3D vs. 2D Vision in a Virtual Learning Environment. Eur. J. Dent. Educ. 2016, 20, 142-147. [CrossRef]

24. Kwon, H.-B.; Park, Y.-S.; Han, J.-S. Augmented Reality in Dentistry: A Current Perspective. Acta Odontol. Scand. 2018, 76, 497-503. [CrossRef] [PubMed]

25. Vávra, P.; Roman, J.; Zonča, P.; Ihnát, P.; Němec, M.; Kumar, J.; Habib, N.; El-Gendi, A. Recent Development of Augmented Reality in Surgery: A Review. J. Healthc. Eng. 2017, 2017. [CrossRef]

26. Yamaguchi, S.; Ohtani, T.; Ono, S.; Yamanishi, Y.; Sohmura, T.; Yatani, H. Intuitive Surgical Navigation System for Dental Implantology by Using Retinal Imaging Display. Implant. Dent. Rapidly Evol. Pract. 2011. [CrossRef]

27. Durham, M.; Engel, B.; Ferrill, T.; Halford, J.; Singh, T.P.; Gladwell, M. Digitally Augmented Learning in Implant Dentistry. Oral Maxillofac. Surg. Clin. N. Am. 2019, 31, 387-398. [CrossRef]

28. Jo, Y.-J.; Choi, J.-S.; Kim, J.; Kim, H.-J.; Moon, S.-Y. Virtual Reality (VR) Simulation and Augmented Reality (AR) Navigation in Orthognathic Surgery: A Case Report. Appl. Sci. 2021, 11, 5673. [CrossRef]

29. Ayoub, A.; Pulijala, Y. The Application of Virtual Reality and Augmented Reality in Oral \& Maxillofacial Surgery. BMC Oral Health 2019, 19, 238. [CrossRef]

30. Choi, J.-W.; Lee, J.Y. Virtual Surgical Planning and Three-Dimensional Simulation in Orthognathic Surgery. In The Surgery-First Orthognathic Approach: With Discussion of Occlusal Plane-Altering Orthognathic Surgery; Choi, J.-W., Lee, J.Y., Eds.; Springer: Singapore, 2021; pp. 159-183. ISBN 9789811575419.

31. Fushima, K.; Kobayashi, M. Mixed-Reality Simulation for Orthognathic Surgery. Maxillofac. Plast. Reconstr. Surg. 2016, $38,13$. [CrossRef]

32. Kim, Y.; Kim, H.; Kim, Y. Virtual Reality and Augmented Reality in Plastic Surgery: A Review. Arch. Plast. Surg. 2017, 44, 179. [CrossRef] [PubMed]

33. Arikatla, V.S.; Tyagi, M.; Enquobahrie, A.; Nguyen, T.; Blakey, G.H.; White, R.; Paniagua, B. High Fidelity Virtual Reality Orthognathic Surgery Simulator. Proc. SPIE Int. Soc. Opt. Eng. 2018, 10576, 1057612. [CrossRef]

34. Khanagar, S.B.; Al-Ehaideb, A.; Vishwanathaiah, S.; Maganur, P.C.; Patil, S.; Naik, S.; Baeshen, H.A.; Sarode, S.S. Scope and Performance of Artificial Intelligence Technology in Orthodontic Diagnosis, Treatment Planning, and Clinical Decision-MakingA Systematic Review. J. Dent. Sci. 2021, 16, 482-492. [CrossRef] [PubMed]

35. Weinstein, P.; Milgrom, P.; Getz, T. Treating Fearful Dental Patients: A Practical Behavioral Approach. J. Dent. Pract. Adm. 1987, 4, 140-147.

36. Getka, E.J.; Glass, C.R. Behavioral and Cognitive-Behavioral Approaches to the Reduction of Dental Anxiety. Behav. Ther. 1992, 23, 433-448. [CrossRef]

37. Gauthier, J.; Savard, F.; Hallé, J.-P.; Dufour, L. Flooding and Coping Skills Training in the Management of Dental Fear. Scand. J. Behav. Ther. 1985, 14, 3-15. [CrossRef]

38. Raghav, K.; Van Wijk, A.J.; Abdullah, F.; Islam, M.N.; Bernatchez, M.; De Jongh, A. Efficacy of Virtual Reality Exposure Therapy for Treatment of Dental Phobia: A Randomized Control Trial. BMC Oral Health 2016, 16, 25. [CrossRef] [PubMed]

39. Krijn, M.; Emmelkamp, P.M.G.; Olafsson, R.P.; Biemond, R. Virtual Reality Exposure Therapy of Anxiety Disorders: A Review. Clin. Psychol. Rev. 2004, 24, 259-281. [CrossRef]

40. Baus, O.; Bouchard, S. Moving from Virtual Reality Exposure-Based Therapy to Augmented Reality Exposure-Based Therapy: A Review. Front. Hum. Neurosci. 2014, 8, 112. [CrossRef]

41. Custódio, N.B.; Costa, F.D.S.; Cademartori, M.G.; da Costa, V.P.P.; Goettems, M.L. Effectiveness of Virtual Reality Glasses as a Distraction for Children During Dental Care. Pediatr. Dent. 2020, 42, 93-102.

42. Vassend, O.; Willumsen, T.; Hoffart, A. Effects of Dental Fear Treatment on General Distress. The Role of Personality Variables and Treatment Method. Behav. Modif. 2000, 24, 580-599. [CrossRef] [PubMed]

43. Berggren, U. Reduction of Fear and Anxiety in Adult Fearful Patients. Int. Dent. J. 1987, 37, 127-136. [PubMed]

44. Hoffman, H.G.; Sharar, S.R.; Coda, B.; Everett, J.J.; Ciol, M.; Richards, T.; Patterson, D.R. Manipulating Presence Influences the Magnitude of Virtual Reality Analgesia. Pain 2004, 111, 162-168. [CrossRef] [PubMed]

45. Hoffman, H.G.; Garcia-Palacios, A.; Patterson, D.R.; Jensen, M.; Furness, T.; Ammons, W.F. The Effectiveness of Virtual Reality for Dental Pain Control: A Case Study. Cyberpsychol. Behav. 2001, 4, 527-535. [CrossRef] 
46. Gujjar, K.R.; Sharma, R.; Jongh, A.D. Virtual Reality Exposure Therapy for Treatment of Dental Phobia. Dent. Update 2017, 44, 423-435. [CrossRef] [PubMed]

47. Gujjar, K.R.; van Wijk, A.; Sharma, R.; de Jongh, A. Virtual Reality Exposure Therapy for the Treatment of Dental Phobia: A Controlled Feasibility Study. Behav. Cogn. Psychother. 2018, 46, 367-373. [CrossRef]

48. Heidari, E.; Newton, J.T.; Banerjee, A. Minimum Intervention Oral Healthcare for People with Dental Phobia: A Patient Management Pathway. Br. Dent. J. 2020, 229, 417-424. [CrossRef]

49. Felemban, O.M.; Alshamrani, R.M.; Aljeddawi, D.H.; Bagher, S.M. Effect of Virtual Reality Distraction on Pain and Anxiety during Infiltration Anesthesia in Pediatric Patients: A Randomized Clinical Trial. BMC Oral Health 2021, 21, 321. [CrossRef]

50. Hendrix, C.; Barfield, W. The Sense of Presence within Auditory Virtual Environments. Presence Teleoperators Virtual Environ. 1996, 5, 290-301. [CrossRef]

51. Rajguru, C.; Obrist, M.; Memoli, G. Spatial Soundscapes and Virtual Worlds: Challenges and Opportunities. Front. Psychol. 2020 11, 569056. [CrossRef]

52. Stein, C.; Santos, N.M.L.; Hilgert, J.B.; Hugo, F.N. Effectiveness of Oral Health Education on Oral Hygiene and Dental Caries in Schoolchildren: Systematic Review and Meta-Analysis. Community Dent. Oral Epidemiol. 2018, 46, 30-37. [CrossRef] [PubMed]

53. Ghaffari, M.; Rakhshanderou, S.; Ramezankhani, A.; Noroozi, M.; Armoon, B. Oral Health Education and Promotion Programmes: Meta-Analysis of 17-Year Intervention. Int. J. Dent. Hyg. 2018, 16, 59-67. [CrossRef]

54. Jimenez, Y.A.; Cumming, S.; Wang, W.; Stuart, K.; Thwaites, D.I.; Lewis, S.J. Patient Education Using Virtual Reality Increases Knowledge and Positive Experience for Breast Cancer Patients Undergoing Radiation Therapy. Support. Care Cancer 2018, 26, 2879-2888. [CrossRef]

55. Bekelis, K.; Calnan, D.; Simmons, N.; MacKenzie, T.A.; Kakoulides, G. Effect of an Immersive Preoperative Virtual Reality Experience on Patient Reported Outcomes: A Randomized Controlled Trial. Ann. Surg. 2017, 265, 1068-1073. [CrossRef]

56. Lombardi, R.E. The Principles of Visual Perception and Their Clinical Application to Denture Esthetics. J. Prosthet. Dent. 1973, 29, 358-382. [CrossRef]

57. Moussa, C.; Hardan, L.; Kassis, C.; Bourgi, R.; Devoto, W.; Jorquera, G.; Panda, S.; Abou Fadel, R.; Cuevas-Suárez, C.E.; LukomskaSzymanska, M. Accuracy of Dental Photography: Professional vs. Smartphone's Camera. BioMed Res. Int. 2021, 2021, e3910291. [CrossRef]

58. Grischke, J.; Johannsmeier, L.; Eich, L.; Griga, L.; Haddadin, S. Dentronics: Towards Robotics and Artificial Intelligence in Dentistry. Dent. Mater. 2020, 36, 765-778. [CrossRef] [PubMed]

59. Nguyen, T.T.; Larrivée, N.; Lee, A.; Bilaniuk, O.; Durand, R. Use of Artificial Intelligence in Dentistry: Current Clinical Trends and Research Advances. J. Can. Dent. Assoc. 2021, 87, 17. [PubMed]

60. Abouzeid, H.L.; Chaturvedi, S.; Abdelaziz, K.M.; Alzahrani, F.A.; AlQarni, A.A.S.; Alqahtani, N.M. Role of Robotics and Artificial Intelligence in Oral Health and Preventive Dentistry-Knowledge, Perception and Attitude of Dentists. Oral Health Prev. Dent. 2021, 19, 353-363. [CrossRef] [PubMed]

61. Park, W.J.; Park, J.-B. History and Application of Artificial Neural Networks in Dentistry. Eur. J. Dent. 2018, 12, 594-601. [CrossRef] [PubMed]

62. Ahmed, N.; Abbasi, M.S.; Zuberi, F.; Qamar, W.; Halim, M.S.B.; Maqsood, A.; Alam, M.K. Artificial Intelligence Techniques: Analysis, Application, and Outcome in Dentistry-A Systematic Review. BioMed Res. Int. 2021, 2021, 9751564. [CrossRef]

63. Hung, M.; Voss, M.W.; Rosales, M.N.; Li, W.; Su, W.; Xu, J.; Bounsanga, J.; Ruiz-Negrón, B.; Lauren, E.; Licari, F.W. Application of Machine Learning for Diagnostic Prediction of Root Caries. Gerodontology 2019, 36, 395-404. [CrossRef]

64. Udod, O.A.; Voronina, H.S.; Ivchenkova, O.Y. Application of Neural Network Technologies in the Dental Caries Forecast. Wiadomosci Lek. Wars. Pol. 2020, 73, 1499-1504. [CrossRef]

65. Tandon, D.; Rajawat, J.; Banerjee, M. Present and Future of Artificial Intelligence in Dentistry. J. Oral Biol. Craniofacial Res. 2020, 10, 391-396. [CrossRef]

66. Schwendicke, F.; Krois, J. Data Dentistry: How Data Are Changing Clinical Care and Research. J. Dent. Res. 2021, 220345211020265. [CrossRef]

67. Lee, J.-H.; Kim, D.-H.; Jeong, S.-N.; Choi, S.-H. Detection and Diagnosis of Dental Caries Using a Deep Learning-Based Convolutional Neural Network Algorithm. J. Dent. 2018, 77, 106-111. [CrossRef] [PubMed]

68. Gürel, G.; Paolucci, B.; Iliev, G.; Filtchev, D.; Schayder, A. The Fifth Dimension in Esthetic Dentistry. Int. J. Esthet. Dent. 2021, 16, 10-32. [PubMed]

69. Schwendicke, F.; Elhennawy, K.; Paris, S.; Friebertshäuser, P.; Krois, J. Deep Learning for Caries Lesion Detection in Near-Infrared Light Transillumination Images: A Pilot Study. J. Dent. 2020, 92, 103260. [CrossRef]

70. Casalegno, F.; Newton, T.; Daher, R.; Abdelaziz, M.; Lodi-Rizzini, A.; Schürmann, F.; Krejci, I.; Markram, H. Caries Detection with Near-Infrared Transillumination Using Deep Learning. J. Dent. Res. 2019, 98, 1227-1233. [CrossRef]

71. Aubreville, M.; Knipfer, C.; Oetter, N.; Jaremenko, C.; Rodner, E.; Denzler, J.; Bohr, C.; Neumann, H.; Stelzle, F.; Maier, A. Automatic Classification of Cancerous Tissue in Laserendomicroscopy Images of the Oral Cavity Using Deep Learning. Sci. Rep. 2017, 7, 11979. [CrossRef]

72. Johari, M.; Esmaeili, F.; Andalib, A.; Garjani, S.; Saberkari, H. Detection of Vertical Root Fractures in Intact and Endodontically Treated Premolar Teeth by Designing a Probabilistic Neural Network: An Ex Vivo Study. Dentomaxillofacial Radiol. 2016, 46, 20160107. [CrossRef] 
73. Ekert, T.; Krois, J.; Meinhold, L.; Elhennawy, K.; Emara, R.; Golla, T.; Schwendicke, F. Deep Learning for the Radiographic Detection of Apical Lesions. J. Endod. 2019, 45, 917-922.e5. [CrossRef] [PubMed]

74. Fukuda, M.; Inamoto, K.; Shibata, N.; Ariji, Y.; Yanashita, Y.; Kutsuna, S.; Nakata, K.; Katsumata, A.; Fujita, H.; Ariji, E. Evaluation of an Artificial Intelligence System for Detecting Vertical Root Fracture on Panoramic Radiography. Oral Radiol. 2020, 36, 337-343. [CrossRef]

75. Wu, Y.; Wang, F.; Fan, S.; Chow, J.K.-F. Robotics in Dental Implantology. Oral Maxillofac. Surg. Clin. N. Am. 2019, 31, 513-518. [CrossRef]

76. Yuan, F.S.; Wang, Y.; Zhang, Y.P.; Sun, Y.C.; Wang, D.X.; Lyu, P.J. Study on the Appropriate Parameters of Automatic Full Crown Tooth Preparation for Dental Tooth Preparation Robot. Zhonghua Kou Qiang Yi Xue Za Zhi 2017, 52, $270-273$.

77. Adel, S.; Zaher, A.; El Harouni, N.; Venugopal, A.; Premjani, P.; Vaid, N. Robotic Applications in Orthodontics: Changing the Face of Contemporary Clinical Care. BioMed Res. Int. 2021, 2021, e9954615. [CrossRef] [PubMed]

78. Ferrari, R. Writing Narrative Style Literature Reviews. Med. Writ. 2015, 24, 230-235. [CrossRef]

79. Tiu, J.; Cheng, E.; Hung, T.-C.; Yu, C.-C.; Lin, T.; Schwass, D.; Al-Amleh, B. Effectiveness of Crown Preparation Assessment Software As an Educational Tool in Simulation Clinic: A Pilot Study. J. Dent. Educ. 2016, 80, 1004-1011. [CrossRef]

80. Makransky, G.; Petersen, G.B. The Cognitive Affective Model of Immersive Learning (CAMIL): A Theoretical Research-Based Model of Learning in Immersive Virtual Reality. Educ. Psychol. Rev. 2021, 33, 937-958. [CrossRef]

81. Radianti, J.; Majchrzak, T.A.; Fromm, J.; Wohlgenannt, I. A Systematic Review of Immersive Virtual Reality Applications for Higher Education: Design Elements, Lessons Learned, and Research Agenda. Comput. Educ. 2020, 147, 103778. [CrossRef]

82. Meola, A.; Cutolo, F.; Carbone, M.; Cagnazzo, F.; Ferrari, M.; Ferrari, V. Augmented Reality in Neurosurgery: A Systematic Review. Neurosurg. Rev. 2017, 40, 537-548. [CrossRef]

83. Amantini, S.N.S.R.; Montilha, A.A.P.; Antonelli, B.C.; Leite, K.T.M.; Rios, D.; Cruvinel, T.; Lourenço Neto, N.; Oliveira, T.M.; Machado, M.A.A.M. Using Augmented Reality to Motivate Oral Hygiene Practice in Children: Protocol for the Development of a Serious Game. JMIR Res. Protoc. 2020, 9. [CrossRef] [PubMed]

84. Pandrangi, V.C.; Gaston, B.; Appelbaum, N.P.; Albuquerque, F.C.; Levy, M.M.; Larson, R.A. The Application of Virtual Reality in Patient Education. Ann. Vasc. Surg. 2019, 59, 184-189. [CrossRef]

85. Alauddin, M.S.; Baharuddin, A.S.; Mohd Ghazali, M.I. The Modern and Digital Transformation of Oral Health Care: A Mini Review. Healthc. Basel Switz. 2021, 9, 118. [CrossRef] [PubMed]

86. Khanagar, S.B.; Al-ehaideb, A.; Maganur, P.C.; Vishwanathaiah, S.; Patil, S.; Baeshen, H.A.; Sarode, S.C.; Bhandi, S. Developments, Application, and Performance of Artificial Intelligence in Dentistry-A Systematic Review. J. Dent. Sci. 2021, 16, 508-522. [CrossRef] [PubMed]

87. Weinbaum (Weaver), D.; Veitas, V. Open Ended Intelligence: The Individuation of Intelligent Agents. J. Exp. Theor. Artif. Intell. 2017, 29, 371-396. [CrossRef]

88. Revilla-León, M.; Gómez-Polo, M.; Vyas, S.; Barmak, A.B.; Özcan, M.; Att, W.; Krishnamurthy, V.R. Artificial Intelligence Applications in Restorative Dentistry: A Systematic Review. J. Prosthet. Dent. 2021. [CrossRef] [PubMed]

89. Buchner, J.; Buntins, K.; Kerres, M. The Impact of Augmented Reality on Cognitive Load and Performance: A Systematic Review. J. Comput. Assist. Learn. 2021, 38, 285-303. [CrossRef] 